\section{(6) \\ OPEN ACCESS}

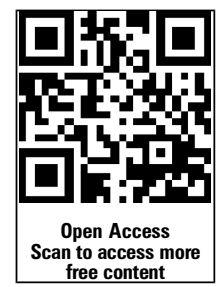

Handling editor Tore K Kvien

- Additional material is

published online only. To view please visit the journal online (http://dx.doi.org/10.1136/ annrheumdis-2013-203695)

${ }^{1}$ University of Toronto, Toronto, Canada

${ }^{2}$ Academic Medical Center Amsterdam \& Atrium Medical Center, Heerlen, The

Netherlands

${ }^{3}$ Karolinska Institute

Stockholm, Sweden

${ }^{4}$ Montpellier University

Hospital, Montpellier, France

${ }^{5}$ Stanford University, Palo Alto, California, USA

${ }^{6}$ Swedish Medical Center and University of Washington, Seattle, Washington, USA ${ }^{7}$ UCB Pharma, Raleigh,

North Carolina, USA

${ }^{8}$ Leiden University Medical

Center, Leiden,

The Netherlands

\section{Correspondence to} Dr Edward Keystone, The Rebecca MacDonald Centre for Arthritis \&

Autoimmune Diseases, Mount Sinai Hospital, 60 Murray St.,

Room 2-006, Box 4, Toronto, ON, Canada M5T 3L9. edkeystone@mtsinai.on.ca

Received 27 March 2013 Revised 5 July 2013 Accepted 15 July 2013 Published Online First 5 August 2013

\section{CrossMark}

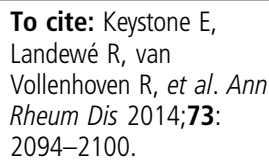

\title{
Long-term safety and efficacy of certolizumab pegol in combination with methotrexate in the treatment of rheumatoid arthritis: 5-year results from the RAPID 1 trial and open-label extension
}

\author{
Edward Keystone, ${ }^{1}$ Robert Landewé, ${ }^{2}$ Ronald van Vollenhoven, ${ }^{3}$ Bernard Combe, ${ }^{4}$ \\ Vibeke Strand ${ }_{1}^{5}$ Philip Mease, ${ }^{6}$ Laura Shaughnessy, ${ }^{7}$ Brenda VanLunen, ${ }^{7}$ \\ Désirée van der Heijde ${ }^{8}$
}

\section{ABSTRACT}

Objectives To examine the safety and efficacy of

5-year administration of certolizumab pegol (CZP)

+methotrexate (MTX) in patients with active rheumatoid arthritis (RA).

Methods Eligible patients from the Rheumatoid Arthritis Prevention of Structural Damage (RAPID) 1 randomised controlled trial (RCT) were treated in openlabel extension (OLE) with CZP 400 mg every other week $(\mathrm{Q} 2 \mathrm{~W})$, reduced to $200 \mathrm{mg} \mathrm{Q} 2 \mathrm{~W}$ after $\geq 6$ months, + MTX. Combined safety data from RCT and OLE are presented from initiation of CZP treatment to 12 wks post last visit in patients receiving $\geq 1$ dose of CZP (Safety population, $\mathrm{N}=958$ ). Efficacy data are presented to start of first site closure (wk 256 of CZP treatment: 52 wks in $\mathrm{RCT}+204$ wks in OLE) for all patients randomised to receive CZP (intent-to-treat (ITT) population, $\mathrm{N}=783$ ) and CZP patients who completed the 52 wk RCT and enrolled into OLE (wK 52 CZP completers, $N=508$ ). Disease Activity Score (DAS)28 (Erythrocyte Sedimentation Rate $(E S R))$, American College of Rheumatology Criteria (ACR) 20/50/70, Health Assessment Questionnaire - Disability Index (HAQ-DI), and patient retention (Kaplan-Meier analysis) were assessed.

Results Overall event rate per 100 patient-years (ER) of adverse events (AEs) was 290.4, most frequently: urinary tract infections ( $E R=7.9)$, nasopharyngitis $(E R=7.3)$ and upper respiratory tract infections $(E R=7.3)$. ER of serious AEs was 20.3 (infections=5.9, malignancies=1.2).

21 patients (2.2\%) experienced an AE resulting in death (incidence rate=0.6). At wk 256 of treatment, $55.3 \%$ of the CZP ITT population were estimated to remain on treatment $(68.7 \%$ if solely withdrawals due to $\mathrm{AE}$ or lack of efficacy were considered). In wk 52 CZP completers and CZP ITT population, DAS28 (ESR) remission rates and improvements from baseline were sustained to wk 256.

Conclusions CZP+MTX treatment provided a

favourable risk-benefit profile over 5 years in patients with active RA. No new safety signals were identified.

\section{INTRODUCTION}

Given the chronic nature of rheumatoid arthritis (RA), treatments must have a favourable long-term risk-benefit profile. Anti-tumor necrosis factor (anti-TNF) therapies provide a valuable option for patients. $^{1-4}$
Certolizumab pegol (CZP) is a PEGylated Fc-free anti-TNF approved for adults with moderate to severe RA. In a 52-week, phase III, double-blind, randomised controlled trial (RCT), Rheumatoid Arthritis Prevention of Structural Damage (RAPID) 1,5 CZP $400 \mathrm{mg}$ or $200 \mathrm{mg}$ every other week $(\mathrm{Q} 2 \mathrm{~W})+$ methotrexate (MTX) provided rapid and sustained improvements in signs and symptoms of disease and inhibition of radiographic damage in patients with active RA.

Patients who completed the RCT and those required to withdraw at week 16 due to American College of Rheumatology Criteria (ACR)20 nonresponse were eligible to enter an open-label extension (OLE).

An initial report, presenting 2-year data from RAPID 1 (1 year of RCT and 1 year of OLE), was published. ${ }^{6}$ Here, we present extended safety data over 6.5 years of CZP+MTX treatment, and efficacy data over 5 years ( 1 year of RCT and 4 years of OLE). We also report the effect of CZP dose reduction in patients who initially received CZP $400 \mathrm{mg}$ Q2W in the OLE, subsequently reduced to $200 \mathrm{mg}$ Q2W.

\section{MATERIALS AND METHODS}

\section{Study design}

The RAPID 1 OLE was conducted in 22 countries between June 2005 and September 2011. Study designs for the RAPID 1 RCT (NCT00152386) ${ }^{5}$ and OLE (NCT00175877) ${ }^{6}$ have been reported. In the RCT, patients were randomised 2:2:1 to receive either CZP $400 \mathrm{mg}$ or CZP $200 \mathrm{mg}$ Q2W (induction dosing: CZP $400 \mathrm{mg}$ at weeks 0, 2 and 4), or placebo, with concomitant MTX. At OLE entry, patients were treated with CZP $400 \mathrm{mg}$ Q2W + MTX. However, while this OLE was underway, data from two Phase III studies (RAPID 1, ${ }^{5}$ RAPID $2^{7}$ ) demonstrated no additional benefit with CZP $400 \mathrm{mg}$ Q2W versus $200 \mathrm{mg}$ Q2W. Consequently, following a protocol amendment, the CZP dosage in the OLE was reduced from $400 \mathrm{mg}$ to $200 \mathrm{mg}$ Q2W.

Changes in MTX dose were permitted in OLE (if clinically indicated) but MTX discontinuation was not. DMARDs other than MTX and other biological therapies were prohibited throughout both RCT and OLE. 
Informed patient consent and approval by all appropriate ethics committees were obtained for both studies. ${ }^{56}$

\section{Patients}

RAPID 1 inclusion criteria are reported in the primary publication. ${ }^{5}$ Eligible patients had active RA (ACR 1987 criteria $^{8}$ ) of $\geq 6$ months' duration prior to screening and had received MTX for $\geq 6$ months (stable dosage of $\geq 10 \mathrm{mg} /$ week for $\geq 2$ months prior to baseline). Exclusion criteria included diagnosis of other inflammatory arthritis or secondary non-inflammatory arthritis, prior treatment with any biologic therapy within 6 months ( 3 months for etanercept or anakinra), failure to respond to $\geq 1$ prior TNF inhibitor, history of tuberculosis (TB), active or latent $\mathrm{TB}$, a high risk of infection, malignancy, demyelinating disease or blood dyscrasias.

Two populations from the RAPID 1 RCT were eligible to enter the OLE: (1) CZP or placebo patients who completed the 52-week RCT and (2) CZP or placebo patients who were ACR20 non-responders at both weeks 12 and 14 in RCT, and were required to withdraw at week 16 . Upon reconsenting, all patients received OL CZP $400 \mathrm{mg}$ Q2W + MTX.

\section{Safety}

The primary objective of the OLE was to assess the safety of CZP+MTX treatment. Combined safety data from RCT and OLE are presented. The safety population includes all patients who received $\geq 1$ dose of CZP in either study. Data are presented from time of first CZP exposure until last visit, or patient withdrawal plus 12-week follow-up. Adverse events (AE) and serious AEs (SAE) were assessed at every visit and classified by system organ class (SOC) and preferred term (PT) according to the MedDRA dictionary (V.9.0). Exposure-adjusted event rates (ER) and incidence rates (IR) per 100 patient-years (pt-yr) are reported. IRs are presented for AEs typically occurring in individual patients only once (eg, malignancy) with data, including exposure, censored after the first occurrence of a particular event in a patient. IRs do not account for when an individual may remain in the trial after experiencing one or more events of interest (eg, infections) and are therefore only appropriate for AEs of single incidence. As more frequent AEs can occur more than once in individual patients, for completeness, both ERs and IRs are presented for AEs occurring in individual patients more than once. The most frequent AEs (ER > 7.0) and SAEs $(E R>0.25)$ are reported.

\section{Efficacy analyses}

Secondary objectives of the OLE were assessment of the continued tolerability, efficacy and effect on physical function and health outcomes of CZP+MTX.

Efficacy data is reported for two populations: (1) Patients randomised to CZP $400 \mathrm{mg}$ or $200 \mathrm{mg}+$ MTX in the RAPID 1 RCT who completed the 52-week RCT and enrolled into the OLE (week 52 CZP completers), (2) All patients randomised to CZP in the RCT (CZP intent-to-treat (ITT) population).

Efficacy data are presented from baseline of the RAPID 1 RCT to 5 years CZP treatment (eg, for completers, 52 weeks of treatment in RCT followed by 204 weeks in OLE). Efficacy data beyond week 256 are not presented due to a sharp decline in patient numbers, occurring due to site closure as CZP became commercially available. Patient-reported outcomes (PRO) are presented for the week 52 CZP completer population only.

Disease Activity Score (DAS)28 (Erythrocyte Sedimentation Rate, ESR) (Low Disease Activity $(\mathrm{LDA}) \leq 3.2$, remission $\leq 2.6)^{9}$; ACR20/50/70; Health Assessment Questionnaire - Disability
Index (HAQ-DI); ACR/The European League Against Rheumatism (EULAR) Boolean remission (tender joint count $\leq 1$, swollen joint count $\leq 1$, patient's global assessment of disease activity (Patient's Global Assessment of Disease Activity $(\mathrm{PtGA})) \leq 10 \mathrm{~mm}$ and $\mathrm{CRP} \leq 10 \mathrm{mg} / \mathrm{L})^{10}$; PtGA $(100 \mathrm{~mm}$ visual analogue scale (VAS)); and patient's assessment of arthritis pain (VAS) were measured every 12 weeks in the OLE. Fatigue (VAS) and health-related quality of life (HRQoL; assessed by SF-36) were measured at weeks 12,24 and every 24 weeks in OLE. Continuous measures are presented as absolute scores and change from RCT baseline.

The dose reduction population subset includes all RAPID 1 week 52 CZP $400 \mathrm{mg}$ and $200 \mathrm{mg}$ completers who received CZP $400 \mathrm{mg}$ Q2W +MTX for $\geq 6$ months in the OLE and had the CZP dose reduced to $200 \mathrm{mg}$ Q2W. Dose reduction data are presented over 204 weeks of CZP exposure following dose reduction.

\section{Statistical analyses}

Dichotomous data were imputed by modified non-responder imputation (mNRI), whereby missing data due to patient withdrawal secondary to an AE, lack of efficacy or use of rescue medication were imputed by NRI; if dichotomous data were missing for reasons other than these, last observation carried forward (LOCF) imputation was applied. If no suitable LOCF value existed, NRI was used. Missing continuous data were imputed by LOCF. Observed ACR20/50/70 data are also presented.

Kaplan-Meier analysis was used to estimate patient retention in CZP ITT patients who withdrew for any reason, and who withdrew due to AE or lack of efficacy. Patients withdrawing for other reasons were censored at time of withdrawal. Patients who did not withdraw were censored at their last scheduled visit.

\section{RESULTS}

\section{Baseline demographics and patient disposition}

Patients in week 52 CZP completer, CZP ITT and dose reduction populations had high disease activity at baseline (mean DAS28 (ESR) for CZP completer, ITT and dose reduction populations; table 1).

Of 783 patients randomised to receive CZP $(400 \mathrm{mg}$ or $200 \mathrm{mg})+$ MTX in the RAPID 1 RCT, 529 (67.6\%) completed 52 weeks and $508(64.9 \%)$ reconsented to OLE treatment (week 52 CZP completers) (figure 1A). Of the week 52 CZP completers, $283(55.7 \%)$ remained in the study at week 256 of CZP treatment. 81 (15.9\%) had withdrawn from the OLE due to AEs or lack of efficacy by this time point; the remaining patients withdrew for reasons including subject decision, loss to follow-up and protocol non-compliance.

The retention rate for the CZP ITT population after 5 years of CZP treatment (accounting for withdrawals for any reason), was $55.3 \%$ (estimated by Kaplan-Meier survival analysis). If only withdrawals due to adverse events or lack of efficacy were considered (ie, patients withdrawing for other reasons were censored at time of discontinuation), the estimated retention rate at week 256 was $68.7 \%$ of the CZP ITT population (figure 1B).

In the OLE, the mean treatment duration on the $400 \mathrm{mg}$ dose was 595 days, and on the $200 \mathrm{mg}$ dose (following dose reduction) was 938 days.

\section{Safety}

Total exposure to CZP (including 12-week safety follow-up) was 3,732 pt-yrs, with $93.8 \%$ of the 958 patients who received CZP reporting AEs during RAPID 1 RCT or OLE (ER=290.4) (table 2). Most (86.6\%) were mild to moderate in nature. The 
Table 1 Baseline demographics and patient characteristics for week 52 CZP completers, the CZP ITT population and the dose-reduction population at the baseline of the RAPID 1 study

\begin{tabular}{|c|c|c|c|}
\hline Characteristic & Week 52 CZP completers* ( $N=508)$ & CZP ITT population ( $\mathrm{N}=783$ ) & Dose reduction population $(\mathrm{N}=436)$ \\
\hline Age, mean (SD), years & $51.5(11.4)$ & $51.9(11.7)$ & $51.3(11.1)$ \\
\hline Gender, \% female & 83.1 & 83.0 & 83.5 \\
\hline Disease duration, mean (SD), years & $6.1(4.1)$ & $6.1(4.3)$ & $6.1(4.1)$ \\
\hline Number of prior DMARDs (except MTX), mean (SD) & $1.3(1.3)$ & $1.3(1.3)$ & $1.2(1.2)$ \\
\hline RF positive ( $\geq 14 \mathrm{IU} / \mathrm{mL}), \%$ & 84.6 & 81.5 & 84.4 \\
\hline Tender/painful joint count, mean (SD) & $31.0(12.7)$ & $30.9(12.8)$ & $31.0(12.4)$ \\
\hline Swollen joint count, mean (SD) & $22.3(9.9)$ & $21.6(9.8)$ & $22.3(9.8)$ \\
\hline Pain VAS, mean (SD) & $63.0(18.0)$ & $62.9(18.7)$ & $63.0(17.9)$ \\
\hline HAQ-DI, mean (SD) & $1.7(0.6)$ & $1.7(0.6)$ & $1.7(0.6)$ \\
\hline DAS28 (ESR), median (min, max) & $7.0(4,9)$ & $6.9(4,9)$ & $7.0(4,9)$ \\
\hline
\end{tabular}

most frequent AEs were urinary tract infections, nasopharyngitis and upper respiratory tract infections (table 2). AEs resulted in deaths in 21 patients $(2.2 \%)(\mathrm{IR}=0.6)$, including 5 deaths due to malignancies, 5 to cardiovascular events and 3 to infections. AEs leading to death were considered by the investigator to be related to study medication in 6 patients: 1 patient each with hepatic cirrhosis, pneumonia, malignancy, stage IV gastric cancer, and disseminated TB, and 1 patient with pyrexia, colon cancer, and metastases to liver and lung. SAEs were reported in 399 patients $(41.6 \%),(E R=20.3)$. The IR for TB infections,

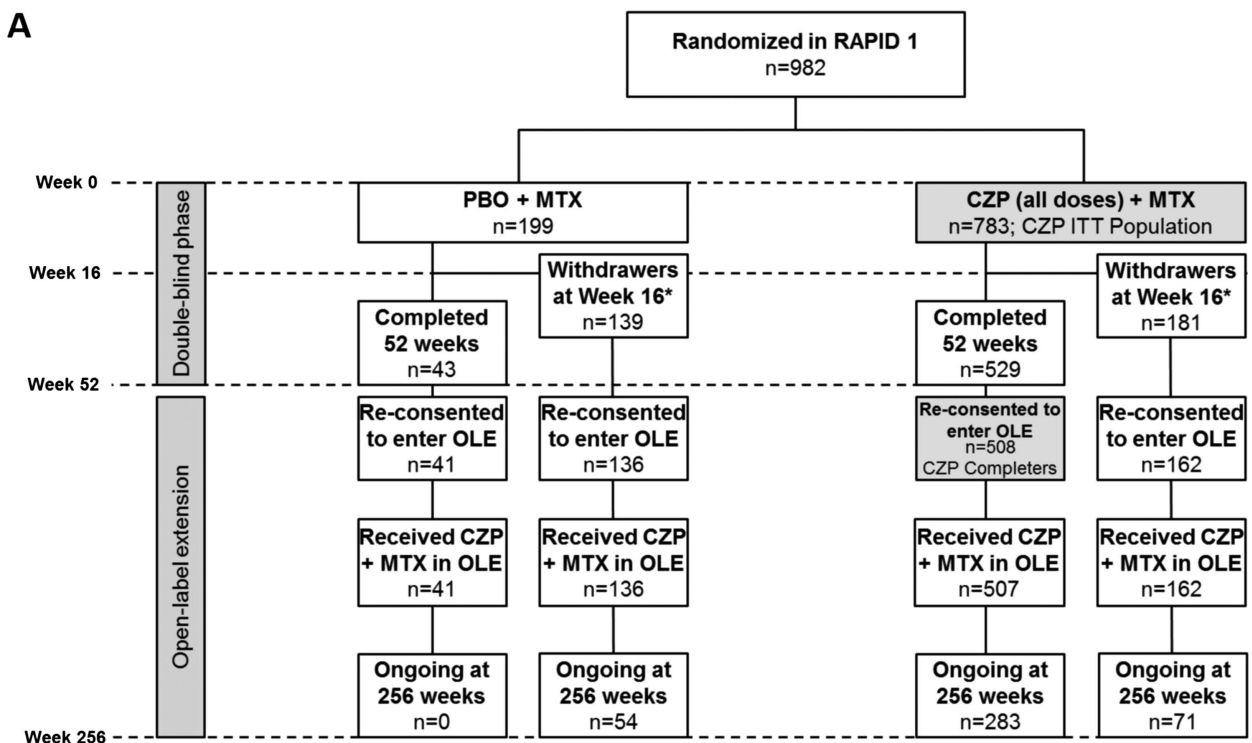

B

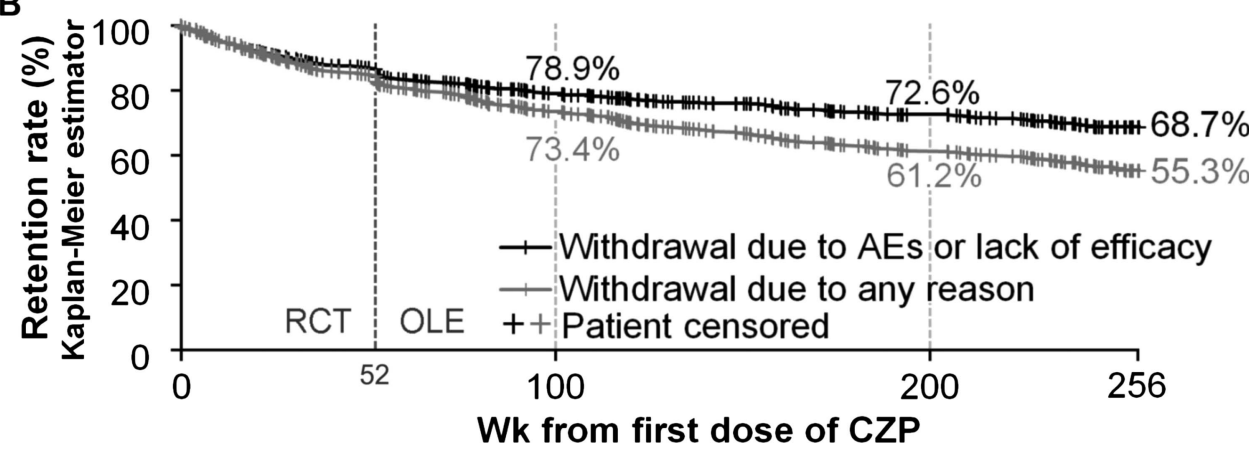

Figure 1 (A) Patient disposition in the Rheumatoid Arthritis Prevention of Structural Damage 1 (RAPID 1) randomised controlled trial and open-label extension and (B) Kaplan-Meier plot of time to withdrawal ${ }^{\dagger}$ for any reason, and due to lack of efficacy or adverse effect from start of feeder study for the certolizumab pegol (CZP) intent-to-treat (ITT) population ( $N=783)$. *Withdrew from the study at week 16 per protocol; efficacy populations (CZP ITT patients and CZP completers) are highlighted. ${ }^{+}$Time to withdrawal is measured from the point at which a patient is first treated with CZP. 
Table 2 Summary of adverse events in all patients treated with CZP in the RAPID 1 RCT and OLE (safety population)

\begin{tabular}{|c|c|c|c|c|}
\hline Adverse event & No. of Pts $(\%)^{*} \mathrm{~N}=958$ & Total number of events & $\begin{array}{l}\text { Event rate (ER) per } \\
100 \text { patient-years }\end{array}$ & $\begin{array}{l}\text { Incidence rate per } \\
100 \text { patient-years }\end{array}$ \\
\hline Total AEs & $899(93.8)$ & 10838 & 290.4 & 144.0 \\
\hline Neoplasms (benign, malignant and unspecified) $\dagger$ & $87(9.1)$ & 105 & 2.8 & 2.4 \\
\hline Infections/Infestations $†$ & $717(74.8)$ & 3130 & 83.9 & 49.0 \\
\hline \multicolumn{5}{|c|}{ Most frequent infections by preferred term (ER $>7.0$ per 100 pt-yrs) } \\
\hline Upper respiratory tract & $144(15.0)$ & 274 & 7.3 & 4.3 \\
\hline Nasopharyngitis & $162(16.9)$ & 273 & 7.3 & 4.9 \\
\hline Urinary tract infections & $161(16.8)$ & 295 & 7.9 & 4.9 \\
\hline AEs leading to withdrawal & $177(18.5)$ & 187 & - & 4.8 \\
\hline AEs leading to death & $21(2.2)$ & 25 & - & 0.6 \\
\hline Total SAEs & $399(41.6)$ & 757 & 20.3 & 13.5 \\
\hline Serious infections/infestations $\uparrow$ & $159(16.6)$ & 219 & 5.9 & 4.6 \\
\hline \multicolumn{5}{|c|}{ Most frequent SAEs by preferred term (ER>0.25 per 100 pt-yrs) } \\
\hline Pneumonia & $34(3.5)$ & 36 & 1.0 & 0.9 \\
\hline Cellulitis & $12(1.3)$ & 13 & 0.4 & 0.3 \\
\hline Cholelithiasis & $11(1.1)$ & 11 & 0.3 & 0.3 \\
\hline
\end{tabular}

including suspected TB, was 0.6. 39 patients experienced SAEs in the SOC neoplasms (including cysts, benign and malignant tumours); excluding non-melanoma skin cancer, 23 of these were considered malignancies following medical review. The most frequent serious malignancies by PT were basal cell carcinoma $(\mathrm{N}=4, \mathrm{IR}=0.1)$ and breast cancer $(\mathrm{N}=3, \mathrm{IR}=0.1)$. No cases of demyelinating disease were reported. AE incidence did not increase over time, and SAE incidence remained approximately constant over the majority of the treatment period (figure 2).

\section{Efficacy}

Improvements in DAS28 (ESR) from RAPID 1 were maintained to 5 years (figure 3A). Mean DAS28 (ESR) at RAPID 1 RCT baseline was 6.92 for both week 52 CZP completers and CZP ITT population, decreasing to 3.58 and 3.98 respectively, after 52 weeks of CZP treatment and sustained to 3.43 and 3.83 after 256 weeks. Mean DAS28 (ESR) change from RAPID 1
RCT baseline at week 52 of treatment was -3.32 and -2.91 for the week 52 CZP completers and CZP ITT population, respectively, and at week 256 was -3.49 and -3.08 .

Rapid improvements in ACR response rates in the RAPID 1 RCT were maintained until week 256 of CZP treatment (figure 3B), with ACR20/50/70 response rates in the week 52 CZP completer population of $74.4 \%, 57.3 \%$ and $39.6 \%$. Observed ACR20/50/70 response rates at week 256 for the CZP completer population were $88.3 \%$ (242/274 patients), 69.0\% (189/274) and $43.4 \%$ (119/274). Analysis of the CZP ITT population gave a more conservative estimate of efficacy, with ACR20/50/70 response rates of $59.0 \%, 43.7 \%$ and $28.8 \%$, at week 256 .

Significant improvements in physical function observed in RAPID 1 were maintained to week 256 of CZP treatment (figure $3 \mathrm{C}$ ). For week $52 \mathrm{CZP}$ completers and CZP ITT population, respectively, the mean change in HAQ-DI from feeder study baseline at week 52 was -0.76 and -0.64 and at week 256 was -0.77 and -0.66 .
Figure 2 Percentage of patients experiencing adverse events (AEs) and serious AEs over each 6-month period from the start of the feeder study (safety population; $\mathrm{N}=958$ ). Note, sharp decline in patient numbers from month 60 is due to per protocol site closure in countries where certolizumab pegol became commercially available.

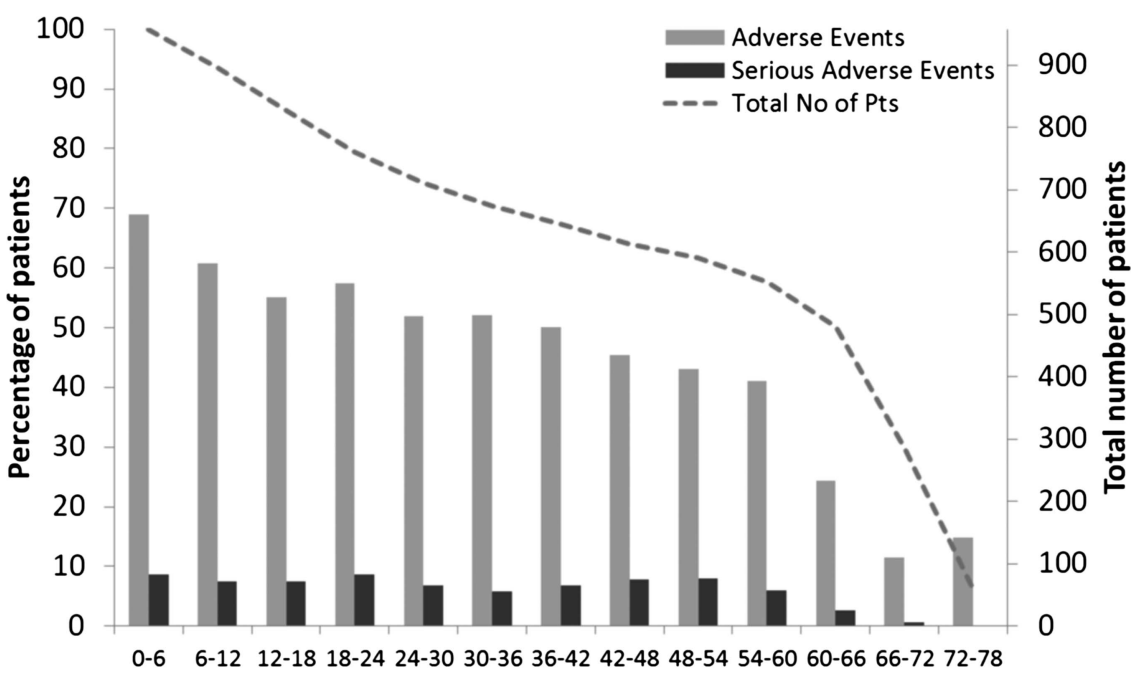

Months 

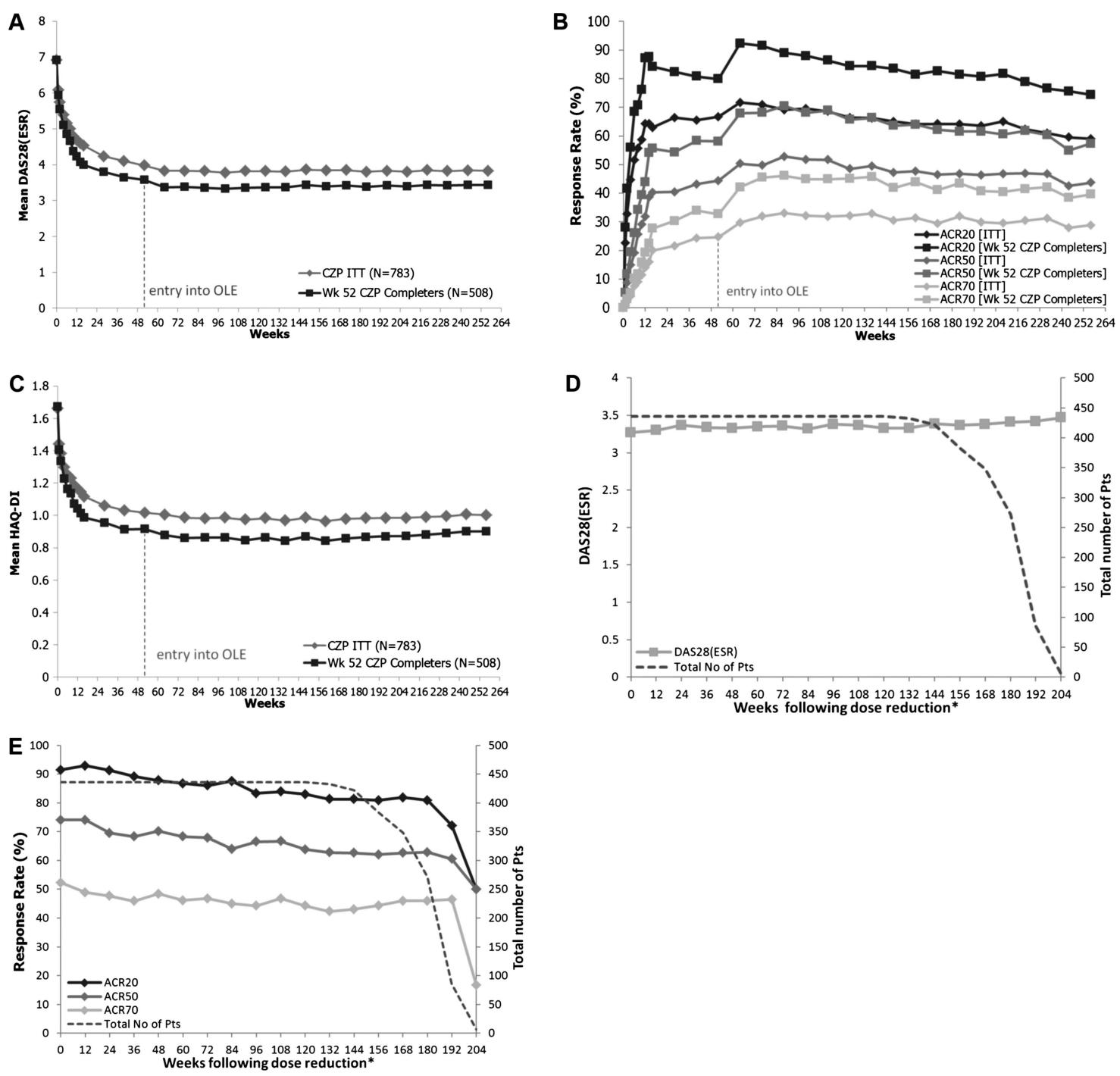

Figure 3 Efficacy variables for week 52 certolizumab pegol (CZP) completers ( $N=508)$ and CZP intent-to-treat population ( $N=783$ ). (A) Mean Disease Activity Score (DAS)28 (Erythrocyte Sedimentation Rate, ESR); (B) American College of Rheumatology Criteria (ACR)20, ACR50 and ACR70 response rates); (C) Mean Health Assessment Questionnaire - Disability Index (HAQ-DI). Efficacy variables in patients following dose reduction from CZP $400 \mathrm{mg}$ Q2W to CZP $200 \mathrm{mg}$ Q2W ( $\mathrm{N}=436$ ). (D) Mean DAS28 (ESR); (E) ACR20, ACR50 and ACR70 response rates. *This analysis is presented as weeks following dose-reduction visit. ('week $0^{\prime}$ is defined as the final efficacy assessment visit where a patient received CZP $400 \mathrm{mg}$ dose.) Total number of patients reflects imputed population. Note, sharp decline in patient numbers from week 144 following dose reduction is due to per protocol site closure in countries where CZP became commercially available.

After 52 weeks of CZP treatment, 24.4\% $(\mathrm{n}=124)$ and $18.6 \%(\mathrm{n}=145)$ of week 52 CZP completers and CZP ITT patients achieved DAS28 (ESR) remission; $41.9 \%$ and $33.5 \%$ achieved LDA. At week 256, 25.2\% $(\mathrm{n}=128)$ and $20.3 \%$ $(\mathrm{n}=158)$, respectively, achieved DAS28 (ESR) remission and $48.7 \%$ and $39.9 \%$ achieved LDA. Furthermore, $15.9 \%$ of week 52 CZP completers $(n=81)$ and $11.7 \%$ of CZP ITT patients $(\mathrm{n}=91)$ achieved ACR/EULAR Boolean remission after 52 weeks of CZP treatment. By week 256 of CZP treatment, this increased to $21.1 \%(n=107)$ and $15.9 \%(n=124)$, respectively.

At OLE entry (week 52), mean change from RCT baseline in pain (VAS) for week 52 CZP completers was -39.6; at week 256 it was -38.3 . The mean change from baseline in PtGA for week 52 CZP completers was -40.6 at week 52 and -38.1 at week 256. For week $52 \mathrm{CZP}$ completers, the mean fatigue scores at weeks 52 and 256 of treatment were 3.2 and 3.5 respectively. (Patient-reported outcome data for the CZP ITT population is included in the online supplementary table S1).
Improvements in patients' HRQoL (by SF-36) reported in RAPID $1^{11}$ were maintained in the OLE for the week 52 CZP completers (mean change from RCT baseline at week 256 of treatment: Mental Component Summary, 5.4; Physical Component Summary, 9.3) (SF-36 data for the CZP ITT population is included in the online supplementary table S1).

Analysis on the dose-reduction population $(\mathrm{N}=436)$ indicated that improvements in DAS28 (ESR) and ACR response rates were maintained over 192 weeks following CZP dose reduction (figure 3D,E).

\section{DISCUSSION}

In the RAPID 1 study, CZP+MTX treatment led to rapid improvements in disease activity and inhibition of structural damage up to 52 weeks in patients with active RA. ${ }^{5}$ The 2 -year data from RAPID 1 and OLE reports that, at week 100, 72.4\% and $77.3 \%$ of week 52 CZP $200 \mathrm{mg}$ and $400 \mathrm{mg}$ completers, respectively, did not have radiographic progression, as defined 
by a change from baseline in van der Heijde modified total Sharp score (mTSS) $\leq 0.5{ }^{6}$ This publication represents the final report of the longest-term data from the RAPID 1 study and its OLE to date, and allows for an assessment of the risk-benefit profile of CZP+MTX treatment over 5 years.

Retention rates in long-term clinical trials provide an indication of the long-term efficacy and tolerability of therapies, and hence are of particular importance in chronic conditions. In this study, patient retention rates were relatively high, highlighting the favourable long-term tolerability profile of CZP, and patient satisfaction with treatment. Retention rates in this study were similar to those observed in other long-term anti-TNF studies. $^{12} 13$ However, as clinical trials represent a highly selected patient population that is closely monitored, care must be taken when comparing retention rates from OLE trials to real-life data, such as registries. The safety profile of CZP remained in line with that observed during the RCT and the rate of AEs decreased over time. There was no increase in the overall rate of serious infections with continued exposure to CZP $(\mathrm{IR}=4.6)$ compared to that observed in the first and second years of CZP treatment in this study (IRs=7.3 and 5.4 between 0-12 and 12-24 months, respectively). ${ }^{6}$ The IRs of SAEs and serious infections were comparable to those observed in other long-term TNF inhibitor studies, ${ }^{14-16}$ although direct comparison is difficult due to differences in study populations and methods of recording AEs. The incidence of malignancies did not increase with additional CZP exposure, and was in line with that expected in the general population. ${ }^{17}$ Long-term CZP treatment was not associated with a change in the type or severity of AEs, and no new safety signals were identified.

Improvements in signs and symptoms, physical function, HRQoL and PROs observed over 52 weeks in the RAPID 1 trial were sustained throughout 5 years. Despite high baseline disease activity, the proportion of week 52 CZP completers achieving DAS28 (ESR) remission in the study was maintained at approximately one quarter (OLE entry: 24.4\%; week 256: 25.2\%). Furthermore, measurable improvements in the rigorous ACR/ EULAR Boolean remission criteria ${ }^{10}$ were observed. However, the mean DAS28 (ESR) score plateaued at approximately 4, an effect previously observed with biologic therapies in established RA, indicating that despite clear benefits with CZP treatment, remission is not achieved in all patients.

Patients in the CZP ITT population also displayed long-term reduction in signs and symptoms of disease in the OLE. The difference in outcomes between this population and the completer population was greater for ACR response rates than DAS28 (ESR) and HAQ-DI, suggesting that disease state measures may be of more use when assessing efficacy in long-term studies.

Dose reduction analysis indicated that the registered dose of CZP $200 \mathrm{mg}$ Q2W + MTX provides sustained clinical efficacy for over 3 years of treatment.

The patient population and imputation methodology applied in long-terms studies can have a considerable impact on the reported data, and hence on inferences about efficacy. An independent taskforce has highlighted the need for an unbiased, consistent and scientifically valid approach. ${ }^{18}$ The analysis of selected patients, who have tolerated and responded to treatment, while providing information on likely outcomes of patients who continue long-term treatment, can introduce a bias. The ITT population, based on all patients, should also be presented. ${ }^{18}$ In line with these recommendations we have presented data analysed both the CZP RCT completer and ITT populations. As would be expected, ACR response rates and measures of remission are lower in the latter population although, even with this more conservative approach, one fifth of patients achieved DAS28 (ESR) remission after 5 years of CZP treatment.

Long-term comparison of interventions is often complicated by publications which contain either no imputation ${ }^{13}{ }^{15}$ or no details of imputation methodology. ${ }^{12}{ }^{19}$ By contrast with other long-term studies which report observed ${ }^{13} 15$ or LOCF ${ }^{20}$ dichotomous data, this publication applies mNRI to missing dichotomous data. A study comparing long-term observed, LOCF and NRI efficacy data clearly demonstrated the conservative nature of NRI, ${ }^{21}$ with a further report suggesting that LOCF can lead to unreasonably high estimates of success in long-term analyses, depending on the reasons for patient withdrawal. ${ }^{22}$ A comparison of observed and NRI data in this study unambiguously demonstrated the more conservative nature of NRI.

\section{CONCLUSIONS}

CZP+MTX had a favourable risk-benefit profile over 5 years of treatment in active RA patients. The long-term safety profile was in line with that previously reported, with no increase in AEs and SAEs, and no new safety signals. The efficacy of CZP in reducing the signs and symptoms of RA and improving physical function was maintained over 5 years. The efficacy of CZP was not affected by dose reduction from $400 \mathrm{mg}$ to $200 \mathrm{mg}$ Q2W.

Acknowledgements The authors acknowledge Marine Champsaur, PhD, UCB Pharma, Brussels, Belgium, for publication management and Costello Medical Consulting for editorial and administrative support.

Funding This manuscript has been funded by UCB Pharma.

Competing interests $E$ Keystone has received grant/research support from: Abbott, Amgen, AstraZeneca, BMS, F Hoffmann-La Roche, Janssen, Lilly, Novartis, Pfizer, UCB Pharma; consultancy fees from: Abbott, AstraZeneca, Biotest, BMS, F Hoffmann-La Roche, Genetech, Janssen, Lilly, Merck, Nycomed, Pfizer, UCB Pharma; and speaker honoraria from: Abbott, Amgen, AstraZeneca, BMS Canada, F Hoffmann-La Roche, Janssen, Pfizer, UCB Pharma. R Landewé has received grant/ research support from: Abbott, Amgen, Centocor, Novartis, Pfizer, Roche, Schering-Plough, UCB Pharma, Wyeth; consultancy fees from: Abbott, Ablynx, Amgen, AstraZeneca, BMS, Centocor, GSK, Novartis, Merck, Pfizer, Roche, Schering-Plough, UCB Pharma, Wyeth; and speaker honoraria from: Abbott, Amgen, BMS, Centocor, Merck, Pfizer, Roche, Schering-Plough, UCB Pharma, Wyeth. R van Vollenhoven has received grant/research support from: Abbott, BMS, GSK, MSD, Pfizer, Roche, UCB Pharma; and consultancy fees from: Abbott, BMS, GSK, MSD, Pfizer, Roche, UCB Pharma. B Combe has received grant/research support from: Merck, Pfizer, Roche-Chugai; consultancy fees from: Merck, Pfizer, Roche-Chugai, UCB Pharma, BMS, Celgene, Lilly, Novartis; and speaker honoraria from: Merck, Pfizer, Roche-Chugai, UCB Pharma, BMS, Celgene, Lilly, Novartis. V Strand has received consultancy fees from UCB Pharma. P Mease has received grant/research support from: Abbott, Amgen, Biogenldec, BMS, Celgene, Janssen, Lilly, Novartis, Pfizer, UCB Pharma; consultancy fees from: Abbott, Amgen, Biogenldec, BMS, Celgene, Janssen, Lilly, Novartis, Pfizer, UCB Pharma; and speaker honoraria from: Abbott, Amgen, Biogenldec, BMS, Celgene, Janssen, Lilly, Novartis, Pfizer, UCB Pharma; L Shaughnessy and B VanLunen are employees of UCB Pharma; D van der Heijde has received consultancy fees from: AbbVie, Amgen, AstraZeneca, Augurex, BMS, Celgene, Centocor, Chugai, Covagen, Daiichi, Eli-Lilly, GSK, Janssen Biologics, Merck, Novartis, Novo-Nordisk, Otsuka, Pfizer, Roche, Sanofi-Aventis, ScheringPlough, UCB Pharma, Vertex; and is owner of Imaging Rheumatology bv.

Ethics approval National and Regional Ethics Committee or Institutional Review Board (Global Study).

Provenance and peer review Not commissioned; externally peer reviewed.

Open Access This is an Open Access article distributed in accordance with the Creative Commons Attribution Non Commercial (CC BY-NC 3.0) license, which permits others to distribute, remix, adapt, build upon this work non-commercially, and license their derivative works on different terms, provided the original work is properly cited and the use is non-commercial. See: http://creativecommons.org/ licenses/by-nc/3.0/

\section{REFERENCES}

1 Moreland LW, Schiff MH, Baumgartner SW, et al. Etanercept therapy in rheumatoid arthritis. A randomized, controlled trial. Ann Intern Med 1999;130:478-86.

2 Weinblatt ME, Keystone EC, Furst DE, et al. Adalimumab, a fully human anti-tumor necrosis factor alpha monoclonal antibody, for the treatment of rheumatoid arthritis 
in patients taking concomitant methotrexate: the ARMADA trial. Arthritis Rheum 2003;48:35-45.

3 van der Heijde D, Landewe R, Klareskog L, et al. Presentation and analysis of data on radiographic outcome in clinical trials: experience from the TEMPO study. Arthritis Rheum 2005;52:49-60.

4 van der Heijde D, Klareskog L, Rodriguez-Valverde V, et al. Comparison of etanercept and methotrexate, alone and combined, in the treatment of rheumatoid arthritis: two-year clinical and radiographic results from the TEMPO study, a double-blind, randomized trial. Arthritis Rheum 2006;54:1063-74.

5 Keystone $E$, van der Heijde D, Mason D Jr, et al. Certolizumab pegol plus methotrexate is significantly more effective than placebo plus methotrexate in active rheumatoid arthritis: findings of a fifty-two-week, phase III, multicenter, randomized, double-blind, placebo-controlled, parallel-group study. Arthritis Rheum 2008:58:3319-29.

6 Keystone EC, Combe B, Smolen J, et al. Sustained efficacy of certolizumab pegol added to methotrexate in the treatment of rheumatoid arthritis: 2-year results from the RAPID 1 trial. Rheumatology (Oxford) 2012;51:1628-38.

7 Smolen J, Landewe RB, Mease $\mathrm{P}$, et al. Efficacy and safety of certolizumab pegol plus methotrexate in active rheumatoid arthritis: the RAPID 2 study. A randomised controlled trial. Ann Rheum Dis 2009;68:797-804.

8 Arnett FC, Edworthy SM, Bloch DA, et al. The American Rheumatism Association 1987 revised criteria for the classification of rheumatoid arthritis. Arthritis Rheum 1988;31:315-24.

9 van Gestel AM, Prevoo ML, van 't Hof MA, et al. Development and validation of the European League Against Rheumatism response criteria for rheumatoid arthritis. Comparison with the preliminary American College of Rheumatology and the World Health Organization/International League Against Rheumatism Criteria. Arthritis Rheum 1996;39:34-40.

10 Felson DT, Smolen JS, Wells G, et al. American College of Rheumatology/European League against Rheumatism provisional definition of remission in rheumatoid arthritis for clinical trials. Ann Rheum Dis 2011;70:404-13.

11 Strand V, Mease P, Burmester GR, et al. Rapid and sustained improvements in healthrelated quality of life, fatigue, and other patient-reported outcomes in rheumatoid arthritis patients treated with certolizumab pegol plus methotrexate over 1 year: results from the RAPID 1 randomized controlled trial. Arthritis Res Ther 2009;11:R170.
12 Weinblatt ME, Keystone EC, Furst DE, et al. Long term efficacy and safety of adalimumab plus methotrexate in patients with rheumatoid arthritis: ARMADA 4 year extended study. Ann Rheum Dis 2006;65:753-9.

13 Nishimoto N, Miyasaka N, Yamamoto K, et al. Long-term safety and efficacy of tocilizumab, an anti-IL-6 receptor monoclonal antibody, in monotherapy, in patients with rheumatoid arthritis (the STREAM study): evidence of safety and efficacy in a 5-year extension study. Ann Rheum Dis 2009;68:1580-4.

14 Genovese MC, Schiff M, Luggen M, et al. Longterm safety and efficacy of abatacept through 5 years of treatment in patients with rheumatoid arthritis and an inadequate response to tumor necrosis factor inhibitor therapy. J Rheumatol 2012;39:1546-54.

15 Smolen JS, Kay J, Landewe RB, et al. Golimumab in patients with active rheumatoid arthritis who have previous experience with tumour necrosis factor inhibitors: results of a long-term extension of the randomised, double-blind, placebo-controlled GO-AFTER study through week 160. Ann Rheum Dis 2012;71:1671-9.

16 Weinblatt ME, Bathon JM, Kremer JM, et al. Safety and efficacy of etanercept beyond 10 years of therapy in North American patients with early and longstanding rheumatoid arthritis. Arthritis Care Res (Hoboken) 2011;63:373-82.

17 Emery P, Breedveld FC, Hall S, et al. Comparison of methotrexate monotherapy with a combination of methotrexate and etanercept in active, early, moderate to severe rheumatoid arthritis (COMET): a randomised, double-blind, parallel treatment trial. Lancet 2008;372:375-82.

18 Buch $\mathrm{MH}$, Aletaha $\mathrm{D}$, Emery $\mathrm{P}$, et al. Reporting of long-term extension studies: lack of consistency calls for consensus. Ann Rheum Dis 2011;70:886-90.

19 Kalden JR, Schattenkirchner M, Sorensen $\mathrm{H}$, et al. The efficacy and safety of leflunomide in patients with active rheumatoid arthritis: a five-year followup study. Arthritis Rheum 2003;48:1513-20.

20 Genovese MC, Bathon JM, Martin RW, et al. Etanercept versus methotrexate in patients with early rheumatoid arthritis: two-year radiographic and clinical outcomes. Arthritis Rheum 2002;46:1443-50.

21 van Lumig PP, Driessen RJ, Kievit W, et al. Results of three analytical approaches on long-term efficacy of etanercept for psoriasis in daily practice. J Am Acad Dermatol 2013;68:57-63

22 Papp KA, Fonjallaz P, Casset-Semanaz F, et al. Analytical approaches to reporting long-term clinical trial data. Curr Med Res Opin 2008;24:2001-8. 